\title{
VOLUNTEER WORK AND LEARNING: HIDDEN DIMENSIONS OF LABOUR FORCE TRAINING
}

\author{
Daniel Schugurensky and Karsten Mundel \\ Ontario Institute for Studies in Education/University of Toronto, CA
}

This chapter explores the links between learning and voluntary work, a topic that is usually absent both in the academic literature and in policy debates. Two reasons may account for the scant attention paid to this issue. First, unpaid work (such as household work and volunteer work) is seldom considered as 'real' work, and therefore the literature on labour force training tends to focus on paid labour, often within the formal sector of the economy. Second, most of the learning connected to volunteer work falls into the category of informal learning, a field that only recently has captured the attention of educational researchers, who traditionally have focussed their efforts on the formal education system. In the late nineties, however, this situation began to change, as the interest of researchers in both areas grew.

In relation to unpaid work, only a few years ago researchers began to document the economic contribution of volunteer work, and the emerging findings are not trivial. A recent study of 22 OECD countries estimates that volunteer contributions (made by approximately $28 \%$ of the population) were equivalent to 10.6 million full-time jobs and their value added amounted to $\$ 840$ billion, representing $3.5 \%$ of the Gross Domestic Product (GDP) of those countries (Salamon et al., 1999). In Canada, volunteer work contributes the equivalent of close to 550,000 full-time jobs per year, which represents $11 \%$ of the total labour contribution, and an addition of about $\$ 13$ billion to the national economy about $1.4 \%$ of the Canadian GDP. Moreover, volunteers contribute significant amounts to the economy in out-of-pocket expenses ( $\$ 841$ million in the late 1980s) that are not reimbursed (Hall, McKeown, \& Roberts, 2001; Statistics Canada, 2001; Ross \& Shillington, 1990; Duchesne, 1989; Quarter, Mook, \& Richmond, 2003). The recognition of the economic and social contribution of volunteer work, compounded with the new awareness of the impressive nature and scope of this contribution, are leading to an understanding that volunteer work is indeed 'real work'.

Regarding informal learning, a few years ago, after a quarter century of relative oblivion, educational researchers began to explore systematically this field once

International Handbook of Educational Policy, 000-000

Nina Bascia, Alister Cumming, Amanda Datnow, Kenneth Leithwood and David Livingstone (eds.)

(C) 2005 Springer. Printed in Great Britain.

bascia0053 15-11-04 11:50:40 Rev. 10*PS

Page Express (Manchester) Limited - Denton, Manchester, UK - 01613207424 
again. One of the most serious initiatives in this regard was conducted between 1996 and 2001 by the New Approaches to Lifelong Learning research network (NALL), led by David Livingstone, a professor at the Ontario Institute for Studies in Education of the University of Toronto (OISE/UT). Building on the pioneering efforts carried out by Alan Tough in the early 1970s at the same institution (Tough, 1971), NALL completed the first extensive national survey of informal learning practices ever conducted in Canada. Five main findings arose from this survey and related exploratory case studies carried out by NALL associates. First, it was found that Canadian adults were engaging in a vast array of informal learning activities in relation to their paid employment, housework, community volunteer work and general interests. This is learning that people reported doing on their own outside any educational institutions or organized courses. Second, it was found that work-related informal learning was much more extensive than participation in adult education courses and programs. Third, the general incidence of informal learning appears to have increased over the past quarter century, from an average of 10 hours per week in the early seventies (as reported by Tough) to 15 hours in the late nineties. Fourth, NALL researchers did not find any strong correlation between informal learning and either formal schooling or participation in adult education courses. Indeed, adults with little formal schooling or adult course participation were just as likely to devote time to informal learning as are the highly schooled. Finally, and this is particularly relevant for this chapter, NALL researchers found a much stronger association between community volunteer work time and community-related informal learning than there is between paid employment time and job-related informal learning. This finding supports the hypothesis that greater discretionary control or self-management can lead to fuller use of workrelated skills and knowledge (Livingstone, 1999).

Although these two bodies of literature (on informal learning and on volunteer work) have been growing significantly lately, connections between them do not abound. While there is an extensive literature on volunteer training programs, as well as on the recruiting and training of volunteers, such literature focuses almost exclusively on the non-formal learning of volunteers. In this chapter, we make an attempt to expand this body of knowledge by bringing to the fore selected issues and policy implications related to informal learning. We will illustrate some of our conceptual discussions with preliminary data arising from our current study on the informal learning of volunteer workers. At the end of the chapter we include a few notes for a research agenda on this topic.

Our discussion is framed in the context of our current study on volunteer learning in three different contexts: community development, housing cooperatives, and the labour market. Our first case study, in conjunction with the Ontario Health Communities Coalition (OHCC), deals with volunteers whose work aims to benefit their communities in some way. The second case study, in conjunction with A Commitment to Training and Employment for Women (ACTEW), explores the learning of immigrants who volunteer in order to gain entry into the labour market. ${ }^{1}$ The third case study, in conjunction with the 
Cooperative Housing Federation of Toronto, is about the learning of housing cooperative board and committee members whose volunteer work is central to the maintenance and survival of the cooperatives. This study is part of a larger project coordinated by the Work and Lifelong Learning Research Network.

\section{Informal Learning}

The concept of informal learning and how is it is distinguished from formal and nonformal education has already been sufficiently discussed in the opening chapter of this collection. We will only discuss here two issues with this threepart taxonomy. First, as most taxonomies, it is to a certain extent arbitrary, and by using one main criterion to distinguish the categories (the setting in which learning takes place), it may not provide a full account of the complex reality of learning. For instance, if we look at the process of learning, and not only at the setting, we note that schools and universities are not only sites of formal learning, but also sites of nonformal and informal learning. Nonformal learning can take place through practica, student clubs and a variety of extracurricular activities. Likewise, significant informal learning can occur (in most cases, does occur) among students through the hidden curriculum and through a variety of interactions with classmates and with other actors of the educational system (authorities, staff, etc.). Differentiating between learning location and learning process helps to recognize that a given learning experience may incorporate more than one of the three categories at the same time. That is, informal and non-formal learning can occur at the same time as formal learning in a school setting just as formal learning can occur outside of a classroom through distance education.

Secondly, the implicit meaning conveyed in the concepts of formal, nonformal and informal learning implies a hierarchy of learning experiences. In this regard, Billet (2001, p. 14) points out that "although unintended, this labelling [of formal, non-formal, and informal] has fostered a view that learning experiences in the workplace are incoherent as being 'informal' and 'incidental', and as failing to furnish critical insights". While Billet is writing from the context of paid workplace learning, the critique is still relevant to other contexts, including volunteer work. As Illich (1970) and other educational critics have commented, informal learning from experience is seldom given the same prestige as learning that is acquired (and accredited) through either formal or non-formal systems. A contributing factor to this phenomenon is that informal learning has been undertheorized and under-researched, largely because it is more difficult to uncover and analyse than formal or non-formal educational activities that have a set curriculum and objectives whose attainment can be identified and evaluated. Indeed, most of informal learning is incorporated as tacit knowledge, which was characterized by Polanyi (1966) as "that which we know but cannot tell." This explains why informal learning has been for a long time a sort of 'black box' about which not much was known.

More recently, however, attempts have been made to explore the internal

bascia0053 15-11-04 11:50:40 Rev. 10*PS

Page Express (Manchester) Limited - Denton, Manchester, UK - 01613207424 
dynamics of informal learning. For instance, considering the criteria of intentionality and awareness, Schugurensky (2000) identified three types of informal learning: self-directed learning (intentional and conscious), incidental learning (unintentional but conscious) and socialization (unintentional and unconscious). Likewise, Livingstone (forthcoming, 2003) divides informal learning into two main types. The first type of informal training, which occurs "when teachers or mentors take responsibility for instructing others without sustained reference to an intentionally-organized body of knowledge in more incidental and spontaneous learning situations, such as guiding them in acquiring job skills or in community development activities" (p. 2). The second type is self-directed or collective informal learning, a residual category for "all other forms of intentional or tacit learning in which we engage either individually or collectively without direct reliance on a teacher or an externally-organized curriculum" (p. 2). Both attempts recognize that within informal learning there is continuum of experiences that can be more or less structured and organized, and that can occur at the individual and at the collective level.

Whereas the taxonomy of learning are not without problems they can be useful to understanding how and what people learn as long as we recognize the fluidity of the boundaries between and the potential simultaneity of the different learning types.

\section{Volunteer Work}

Volunteer work includes a wide range of activities. Among them are organising and supervising events; coaching children and youth; delivering food and clothes to the needy; serving on boards, councils and committees; providing support and healthcare; driving; taking part in canvassing, campaigning and fundraising; protecting the environment and wildlife; teaching and tutoring; raising awareness and advocating on important issues; greeting visitors; doing office work; leading tours and other recreational activities; ushering in religious institutions; assisting the elderly; researching and disseminating information; fighting fires, and doing repairs, maintenance and construction work (Hall, McKeown, \& Roberts, 2001; Ilsley, 1990). Although these examples illustrate what volunteers do, they do not suggest a universal definition of volunteer work. In common usage, volunteer work is understood as work that is freely chosen, unremunerated, and of some benefit to community or society. This understanding provides a good working definition, but two considerations regarding the diversity and complexity of volunteer work (both at the organizational and at the individual level) are pertinent at this point.

First, volunteering tends to be conflated with the voluntary sector, as if they were the same thing, or as if volunteering only occurs through voluntary organizations. While a great deal of volunteer work is indeed done through voluntary organizations, it is important to recognize that there is also widespread volunteer activity in the public sector, in the private sector and in the community at large (Brudney, 1990; Sheard, 1995). Secondly, volunteer work can take different

bascia0053 15-11-04 11:50:40 Rev. 10*PS

Page Express (Manchester) Limited - Denton, Manchester, UK - 01613207424 
forms, and volunteers are motivated (and sometimes coerced) by different circumstances. Let's consider, for instance, teaching literacy on a regular basis, helping a disabled neighbour with certain chores on occasional basis, undertaking an internship in a corporation in order to gain job experience, working outside of regular hours in a non-governmental organization (NGO) in order to complete tasks, participating in a governing board, doing community work as mandated by a government agency, or participating in a social movement against child labour. All these activities can be considered volunteer work according to the general definition, but clearly they are of very different nature. Some of them, like working beyond regular hours or doing long-term internships with negligible educational impact are even borderline cases, and some may consider them unpaid work rather than volunteer work.

While there is an abundance of literature on volunteering and on voluntary organizations, most authors take the definition of volunteer work for granted. Indeed, after reviewing more than 300 articles and reports, Cnaan, Handy, and Wadsworth (1996, p. 369) reported that the term volunteer was seldom defined. Therefore, they undertook a comprehensive study that included a review of 11 widely used definitions. They found four dimensions that were present in those definitions of volunteer work: the voluntary nature of the act, the nature of the reward, the context or auspices under which the volunteering is performed, and who benefits. Within each dimension, two to three categories were identified:

\begin{tabular}{ll} 
Dimension & Categories \\
\hline Free Choice & 1. Free will (the ability to voluntarily choose) \\
& 2. Relatively uncoerced \\
Remuneration & $\begin{array}{l}\text { 3. Obligation to volunteer } \\
\text { 1. None at all }\end{array}$ \\
2. None expected \\
3. Expenses reimbursed \\
4. Stipend/low pay \\
1. Formal \\
Intended beneficiaries & $\begin{array}{l}\text { 2. Informal } \\
\text { 1. Benefit } / \text { help others } / \text { strangers }\end{array}$ \\
& 2. Benefit/help friends or relatives \\
& 3. Benefit oneself (as well)
\end{tabular}

From Cnaan, Handy, \& Wadsworth (1996, p. 371)

In any given context, different profiles of volunteers can be identified, depending on the specific combination of these four dimensions and their categories. In the last instance, claim the authors, the perception of who is a volunteer and who is not boils down to the net cost of the undertaking: "concept of net cost best accounted for the perception of who is a volunteer" (Cnaan et al., 1996, p. 381). 
In their follow-up study that included over 3000 questionnaires administered in Canada, the Netherlands, India, Italy, and the United States, Handy et al. (2000) further developed that thesis. They found that the public perception is that the greater the self-sacrifice the more altruistic the action. Likewise, the more the work benefits strangers (rather than oneself or friends), the more it is totally unpaid, and the more uncoerced it is, the more it will considered a 'true' volunteer activity. The coercion factor also calls into question whether we can even consider an activity as a voluntary one if it is not chosen in total freedom. Indeed, historically the concept of volunteer has been negatively associated with coercion. In the past, a volunteer was one who voluntarily offered to serve in the military, in contrast to those who were under obligation to do so, or were part of a regular army of military force (Oxford English Dictionary, 2003). However, certain degree of coercion is often present in some volunteer activities, sometimes expressed through legal requirements, social and religious mandates, workplace commitments, community expectations and the like. Where to draw the line between 'genuine' and 'coerced' volunteer work is not easy, and the decision probably varies vary from context to context.

In relation to the formal and informal structures in the volunteer experience, Ilsley (1990) makes the following distinction:

Formal voluntarism can be defined as service that is addressed to a social need or needs defined by an organization, performed in a coordinated way in an organizational context, and rewarded by psychological or other benefits. Informal voluntarism is spontaneous expression of service in response to a personally perceived social need, performed freely (without organizational constraints) and often without any thought of reward (p. 5).

The National Survey on Giving, Volunteering and Participating (NSGVP) ${ }^{2}$ makes a simpler distinction in this regard: formal volunteering is unremunerated and freely chosen work done through an organization whereas informal volunteering is done outside the confines of an organization (Hall, McKeown, \& Roberts, 2001). While we recognize the relevance of informal volunteering, in this chapter we focus on formal volunteering.

Previous research into volunteer work and volunteers has also used many other categorizations and distinctions alternately focusing on the nature of the voluntary organization, the role of the voluntary organization in society, and the role volunteering fills in volunteers' lives (e.g., Hustinx \& Lammertyn, 2003; Salamon \& Sokolowski, 2002; Abdennur, 1987; Elsdon, 1995; Elsdon, Reynolds, \& Stewart, 1995; Isley, 1990) In our research in progress on the learning of volunteers, we identified six profiles of volunteers that may correlate with different learning experiences. These six profiles relate to some elements of the definitional and conceptual frameworks mentioned above, and imply different degrees of passion, social pressure and self-interest. Before we delve into them, it is pertinent to note that a given organization may encompass a variety of volunteer profiles, and that a given volunteer may change their profile over time.

bascia0053 15-11-04 11:50:40 Rev. 10*PS

Page Express (Manchester) Limited - Denton, Manchester, UK - 01613207424 
The first profile is the altruistic volunteer. That is the volunteer who is compelled only by a desire to help others, devotes high levels of time and energy to the volunteer work, and gains no personal benefit (other than satisfaction) from the outcomes of the activities undertaken. The more unlikely that the project undertaken benefits the volunteers themselves, as well as their families, friends and communities, the more altruistic is it considered. Altruistic volunteers may be found in international organisations like Amnesty International, Habitat for Humanity, Greenpeace, Doctors without Borders, the Red Cross, Wildlife Fund, Save the Children, Oxfam, the World Coalition Against the Death Penalty, and also in a wide range of national and local organisations.

A second type is the semi-altruistic volunteer. Unlike the fully altruistic type, the semi-altruistic volunteers combine in different ways a desire to help others with an interest for helping themselves and their communities. While fully altruistic volunteers may engage without hesitation in emergency relief efforts and in projects aiming at protecting exotic animals or the rainforest, eliminating hunger or denouncing human rights abuses in places far from home, semialtruistic volunteers are more likely to engage in projects of local community development (from neighbourhood revitalization projects to community gardening to music festivals), in groups advocating for a cause to which they have a personal or family connection (e.g., special education programs, bicycle routes, seniors' rights, etc.), or in recreation/educational activities that involve their own family members or neighbours (e.g., coaching a sport team, teaching ceramics in the local community centre, helping in the school library, etc.).

A third type is the socially-coerced volunteer. In this case, volunteering is to some extent freely chosen, but also done because it is highly expected by others (family, community, workplace, religious institution, the labour market, society at large, etc.). Unlike the altruistic volunteers (who are motivated only by their inner conscience), in this case group identity, social pressure, and the ethos and informal rules of a given community play a central role in the motivation and in the nature of the volunteer experience.

A fourth type is the compulsory volunteer. Perhaps a contradiction in terms, this volunteer work is mandated by legislation or a policy and often supervised by an institution. Some educational institutions require students to do volunteer work in order to graduate. For example, Mexican university students must complete a social service in order to have their degree formally conferred, and Ontario high school students are required to complete at least 40 hours of community service before graduation (Ontario Ministry of Education and Training, 1999, pp. 9-10). Other state agencies can also require people to volunteer in order to receive social assistance such as the Ontario Works program (Government of Ontario, 1997). The justice system is another state agency that mandates volunteer work in the form of community service for those who have committed a small infraction and for inmates in correctional institutions, usually for rehabilitation purposes or in exchange for paying a fine. While the idea of a compulsory volunteer is conceptually an oxymoron (and perhaps should be called unpaid work rather than volunteer work), in the real world it is a category

bascia0053 15-11-04 11:50:40 Rev. 10*PS

Page Express (Manchester) Limited - Denton, Manchester, UK - 01613207424 
that exists, because even though the work is mandated, it is often construed as volunteer work by the institutions, by the volunteers themselves and by the community. Moreover, the fact that it is mandatory does not preclude that the experience could be a good one for the volunteer and/or the community, and that significant learning can occur through the experience. In 2000 , over $7 \%$ of Canada's volunteers were mandated to do so by their school, government, or employer (Hall et al., 2001, p. 39).

A fifth type is the overtime volunteer. This type of volunteer activity is likely most prevalent in voluntary organisations themselves, and in general in the nonprofit sector. In this sector employees put in significant additional work time during the evenings and weekends (or during the rest of the week if they are hired as part-time workers) to fulfil organizational objectives which are not part of their job description or are not expected of them. They do it partly because of their commitment to organisational goals, and partly because the job needs to be done, and it is in this confusing double role of volunteer and employee where the boundary between volunteer work and plain unpaid work is blurred. A possible criterion to distinguish whether overtime unpaid work falls into the category of volunteer work or not is to consider if the worker can be penalised (financial penalties, suspension, termination) or reprimanded for not doing that particular job. The problem is that in real life many employees in the nonprofit sector have a high level of commitment towards their work and the mission of their organization, and it is difficult even for themselves to determine whether they are freely contributing to the work of their organization or whether the are being exploited.

A sixth category is the intern volunteer, who works in an unpaid or poorly paid capacity in order to gain entry into a particular segment of the labour market. At least two variations of this category can be identified: juniors and seniors. The former volunteer because they have no experience in a given field due to age or a career change. The latter volunteer because their experience and/or diplomas are not recognised by potential employers or by a professional association. This is the case for many immigrants whose training and experience in their country of origin are not recognised in the country they have moved to. In both cases, there is no overt coercion for people to volunteer, but the structures and pressures of the labour market make it very difficult to find a paid job without a volunteer experience. Theoretically, the major beneficiaries of the internship are the volunteers themselves, who aimed at increasing their opportunities in the labour market. ${ }^{3}$ In this sense, this category could be understood more as 'unpaid work for self-benefit' than as volunteer work. However, personal benefit and social benefit are not necessarily excluding of each other, especially if the unpaid work performed has a great social and community impact. Moreover, if the intern does not obtain a paid job as a result of the internship, the real self-benefit will be very low even if the motivation to volunteer was based on self-benefit.

It is probably true that these six profiles do not provide a full account of volunteer work, and that they need to be further refined in order to reduce

bascia0053 15-11-04 11:50:40 Rev. 10*PS

Page Express (Manchester) Limited - Denton, Manchester, UK - 01613207424 
overlaps. In any case, the point we are trying to make here is that the world of volunteer work is diverse and complex, and that volunteers are motivated by a variety of reasons that are not necessarily exclusive. For instance, in the most recent Canadian National Survey on Giving, Volunteering, and Participation (NSGVP), the $27 \%$ of citizens of reported to do formal volunteer work were asked about the different reasons that led them to volunteer. Almost all of them $(95 \%)$ reported that they volunteer to help a cause they believe in. More than 8 in $10(81 \%)$ volunteer because they want to put their skills and experience to use. Over two-thirds $(69 \%)$ volunteered because they had been personally affected by the cause the organisation supports. More than half $(57 \%)$ saw volunteering as an opportunity to explore their strengths. Finally, 30\% volunteered because their friends did, $26 \%$ were also fulfilling religious obligations, and $23 \%$ wanted to improve their job opportunities (Hall et al., 2001, p. 43). The existence of a diversity of motivating factors for doing volunteer work presupposes, at least as a hypothesis, a diversity of learning experiences. Available research evidence suggests that volunteers' choice of learning experiences is strongly related to their choice of objects for commitment (Isley 1990, p. 64). In other words, what volunteers learn is closely connected to the type of activities they undertake, and this is largely connected to why they decided to volunteer in the first place.

\section{Learning, Work and Volunteering: Exploring the Connections}

If we look again at the reasons for volunteering reported by the NSGVP, we would notice that learning was not mentioned at all. This is due to the fact that the survey did not included learning in the list of possible responses, so respondents were not given a chance to name learning as a reason for volunteering. It may also be the case that, with the exception of internships, learning is not perceived as an important motivation for volunteering. This hypothesis is supported by recent research on the accreditation and rewarding of volunteer activities (Percy et al., 1998; Cox, 2002). Cox found that "explicitly educational motives are rarely cited as the reason, people engaged in voluntary activity perceive their activities as 'doing' rather than learning" (Cox, 2002, p. 166). Likewise, Percy, Barnes, Graddon, and Machell (1988) found that "an adult may speak about 'learning' as a motive for attending a voluntary organization, but is most likely not to do so" (p. 58). The NSGVP suggests that volunteers are more likely to perceive the opposite connection: $81 \%$ of respondents felt that the volunteering experience let them apply previous learning to a concrete situation. For reasons probably related to the invisibility and the tacit character of informal learning, the connection between learning and volunteering is mostly perceived as a one-way street. The dominant perception is that we learn in school and to some extent in our professional work, and then we can put our acquired knowledge and skills to social use through volunteering.

The learning dimension of volunteer work is not only often ignored by volunteers themselves; it is also outside the radar of researchers and voluntary

bascia0053 15-11-04 11:50:40 Rev. 10*PS

Page Express (Manchester) Limited - Denton, Manchester, UK - 01613207424 
organisations. Eldson et al. (1995), after reviewing the literature on the connection between learning and volunteering (pp. 24-26), concluded that very few studies exist that directly explore the learning that results from volunteering. Ilsley (1990) found that voluntary organisations do not pay much attention to the learning of their volunteer members:

Although most formal volunteer organizations offer training programs, we found that much of the actual learning in volunteer organizations is unplanned. Perhaps relatedly, learning - especially forms of learning other than instrumental/didactic - appears to be undervalued in most volunteer programs. This is highly unfortunate (Ilsley, 1990, p. 71).

One possible way to explore the connections between learning, volunteer work and labour force training is the relationship between volunteer work and paid work. In this regard, in our fieldwork we identified three main different routes taken by volunteers: sequential, simultaneous and intermittent.

The sequential route refers to volunteering either to gain entry into the labour market or after leaving the labour market. There is a clear demographic factor at play here, as young people are more likely to volunteer before joining the formal labour market, and older people are more likely to volunteer after retirement. Having said that, in the movement from unpaid to paid work, we are not only speaking of newcomers to the labour market (who tend to be predominantly youth) but also of more mature people making a career change or needing to gain experience in a new context. The 'training' rationale for volunteering is well understood by youth and newcomers. The National Survey on Giving, Volunteering and Participating found that only 23\% of volunteers agreed that improving job opportunities was a reason for volunteering. However, when we look at the responses given by younger volunteers (15-24) the percentage increases to $55 \%$ (Hall et al., 2001, p. 35). In other words, young volunteers are twice as likely to see a causal connection between volunteering and paid work.

In the sequential mode, people generally volunteer in an organization related to a field they are interested in, either because they want to be working in it or because they have accumulated a great deal of expertise and passion for it. In the first case, the hope is that they will gain new skills (of social or technical nature) or add to their existing repertoire of skills which will make them more attractive to potential employers. In the second case, the expectation is usually to continue the activity in the field, be it to apply their skills to a social purpose, to keep themselves updated and connected to the field, to fill their time, to feel useful or to repay society with good deeds. In sum, in the sequential mode the link between learning and volunteering is quite clear. For the person hoping to enter the labour market, volunteering is an opportunity to learn skills and make connections to facilitate entry into the labour market. For the person leaving the labour market, learning from the workplace is applied to the volunteer context.

The simultaneous route is where volunteering and paid employment - in the

bascia0053 15-11-04 11:50:40 Rev. 10*PS

Page Express (Manchester) Limited - Denton, Manchester, UK - 01613207424 
same or different fields - take place at the same time. This could be a lawyer doing pro bono work, a dentist volunteering in a poor area, an electrician helping to build houses in Habitat for Humanity, a businessperson coaching a basketball team, or a teacher spending time as Big Sister or Brother mentoring a child. In this mode, learning could take place in either setting with learning being transferred from setting to setting as appropriate. The interaction between volunteering and learning is not as clear as in the sequential mode, and particularly nebulous are the ways in which learning acquired through volunteering informs activities in the paid job.

The intermittent route occurs when a person performs similar jobs in the same field for a significant amount of time, sometimes with remuneration and sometimes without. In this mode there is little distinction between paid employment and volunteer work except whether payment is received or not. A typical example of this route is a person who believes strongly in a cause and works for many years raising awareness about such cause. At a certain point the person becomes employed by an expanding non-profit organisation related to that cause, and so the person begins receiving money for doing essentially the same work. This same organization may succeed in getting their cause reflected in legislation and so financial support for the organization wanes leaving the person out of a job. Even without the job, the person continues to be active researching, advocating and raising public awareness for her cause, and eventually may be hired again to do more research, advocacy and education. In this route, it is very difficult to distinguish what learning comes from volunteer work and what from paid employment, and the specific transfer mechanisms from one setting to the other. While this is an interesting route that we identified through our interviews with volunteers in the areas of health promotion and community development, the majority of volunteers use one or both of the first two routes. Several interviewees also reported instances in which the knowledge, skills and/or values acquired through one type of volunteer work were transferred to another type of volunteer work. Like in the volunteer work/paid work relation, this pattern of transference can also follow the sequential, simultaneous or intermittent routes.

A more explicit link between learning and volunteering can be found in service learning, that is, volunteer work mandated by an educational institution. One of the objectives of mandating volunteer service is to encourage students to develop awareness and understanding of civic responsibility and of the role they can play in supporting and strengthening their communities. Although it is recognised that students' volunteer work will benefit communities, its primary purpose is to contribute to students' development (Ontario Ministry of Education and Training, 1999, p.9). However, it is also assumed that the learning of individual students in turn will be of benefit to society in the future. Furthermore, another objective of service learning is to socialize youth into volunteering roles. The assumption behind this strategy is that by becoming volunteers at a young age, participants will be more likely to volunteer throughout their lives. Indeed, in many service learning programs it is expected that the learning acquired through volunteer work relates not only to occupational skills and to the

bascia0053 15-11-04 11:50:40 Rev. 10*PS

Page Express (Manchester) Limited - Denton, Manchester, UK - 01613207424 
economic realm, but also to the social arena (Andersen, 1999). It is also expected that as volunteers become socialized in a culture of social service and community participation, they can also develop-at least in certain types of programs democratic values and practices.

In this regard, connections between volunteer work, civic learning and civic engagement have been identified in the literature on political participation and citizenship learning (Merrifield, 2001; Pateman, 1970; Roker, Player, \& Coleman, 1999; Westheimer \& Kahne, 2002; Schugurensky, 2002). One of the central arguments of participatory democracy advocates like Rousseau, Dewey and Pateman is that the most effective way to learn democracy is by doing it, and that citizens have to be involved in the practice of democracy and not just the theory. This involvement requires a high level of commitment in time and energy devoted to local democratic processes, and this sustained effort can be considered volunteer work. According to some recent studies, participatory democracy has the potential to contribute significantly to the development of an engaged and informed citizenship, as well as to the democratization of the state and other institutions (Abers, 2000; Baiocchi, 1999; Schugurensky, 2001).

In closing, the connections between learning and volunteer work, and between them and paid work, can be explored through a variety of avenues. In the analysis of those connections, it is pertinent to examine the dynamics between structure and agency in the reproduction of social inequality. For instance, volunteers with higher levels of cultural and social capital (Bourdieu, 1986) are more likely to be placed in more intellectually demanding roles and functions. This experience, in turn, can have positive effect in the expansion of their social and cultural capital, and eventually their transferability to economic capital (e.g., higher employability). In some experiments of local democracy, for instance, participants with higher levels of schooling and connections tend to be elected to take a more active role in councils and committees. This experience may be useful to get into paid positions in legislative or executive government offices, in the leadership of political parties, in nonprofits, etc, even if this was not their rationale for joining the process. At the same time, participants who enter the process with lower levels of cultural and social capital, tend to remain at the lower levels of the decision-making structures. Hence the participatory democracy model, although it provides great learning opportunities to all participants, is seldom sufficient to counteract existing inequalities, and sometimes ends up reproducing them by allowing the development of an internal pyramid. ${ }^{4}$ Having said that, anecdotal information also reveals that some organisations do not pay much attention to match the tasks assigned to volunteers with their talents and possibilities, and missing opportunities for benefiting both the organisation and the volunteer are not uncommon.

\section{Informal Learning through Volunteering: What and How do Volunteers Learn?}

The discussion of the previous sections suggests that the diversity and complexity of volunteer experiences make it very difficult to generalise about volunteer 
learning. However, it is safe to point out that that in most cases volunteer learning is particularly significant, probably because of the high degree of relevance and motivation implicated in the learning process. This was one of the key finding of the 1998 NALL survey. The survey also found that people who have been involved in community work over past year (over 40\%) devoted about 4 hours a week on average to community-related informal learning. About two thirds reported learning interpersonal skills, almost $60 \%$ learned communication skills, over half learned about social issues; and over $40 \%$ were learned about organizational/managerial skills (Livingstone, 1999, 2001a, 2001b).

These findings were confirmed by the 2000 Canadian Survey on Giving, Volunteering and Participating (NSGVP), in which the large majority of volunteers $(79 \%)$ reported an increase in interpersonal skills as a result of their volunteering activities. Other skills mentioned, in decreasing order, were communication skills $(68 \%)$, specific knowledge on a particular subject $(63 \%)$ and organizational/managerial skills (57\%). Among the interpersonal skills identified were understanding people better, learning how to motivate others, and learning how to deal with difficult situations. The most frequently mentioned communication skills were public speaking, writing, conducting meetings, and doing public relations. Knowledge was most often acquired in areas such as health, women's issues, political affairs, criminal justice and the environment, all items that correspond with the category 'social issues' of the NALL survey (Hall et al., 2001, p. 45). While this survey did not ask questions about the mode through which the learning was acquired, preliminary data from our own research in progress suggest that most of these skills are the result of incidental informal learning.

Along the same lines were the findings of a large research project with 31 case studies conducted in Britain by Eldson et al. (1995). They reported the existence of significant changes in areas such as personal confidence, empowerment, making constructive relationships, organizational learning, or the ability and willingness to shoulder responsibility. Changes in these five areas were consistently mentioned as the most important learning by an overwhelming majority of interview respondents, regardless of what kind of voluntary organization they belonged to. Moreover, most of this learning was unpremeditated. In their own words:

a trawl of the interviews shows that the great majority of the respondents attached a high value to these unpremeditated learnings and resulting personal change after experiencing them, and indicated that they considered them even more important than the deliberate learning content of their membership (Elsdon et al., 1995, p. 49 original emphasis).

This unpremeditated learning, which corresponds with our category of 'incidental learning' and was referred to by one of our research participants as "accidental learning," is typical informal learning. In our interviews, many volunteers commented that they had seldom made connections before between the

bascia0053 15-11-04 11:50:40 Rev. 10*PS

Page Express (Manchester) Limited - Denton, Manchester, UK - 01613207424 
different volunteer activities and the learning acquired through them, and that they had never realized the amount and quality of the learning until the interview elicited that.

Back to Polanyi's (1966) characterization ("that which we know but cannot tell") this indicates that much of the informal learning from volunteer work results in tacit knowledge that can only be uncovered after some type of introspective exercise - if at all.

Most of informal learning, both in volunteer work and paid work, is acquired 'by doing'. However, the structuring of learning experiences can extend and supplement the contributions of everyday activities. The structuring involves the development of a curriculum and the provision of guided learning by experienced or expert workers (Billet, 2001, p. 175). Sometimes, these structured teaching/ learning processes may have a greater impact than the informal processes. For example, in a study on social movement learning of a Community Shared Agriculture project in Canada, Clover and Hall (2000) found that although the informal learning was extremely important, it was the 'nonformal' education activities organized by GJOBS/CSA [Growing Jobs for Living Coalition/ Community Shared Agriculture] which were the most valuable sources of learning and contributed the most to personal and social transformation.

This finding reminds us of the need to distinguish, at least for research purposes, between non-formal and informal learning processes in voluntary work. In their study of learning in 800 voluntary organizations in England, Percy et al. (1998) grouped learning in voluntary organizations into two groups. Under the first type, which corresponds to our category of non-formal learning, they found teaching, discussion, training, assessment and certification. In the second type, which relates to our category of informal learning, they identified practise learning, apprenticeship learning, ${ }^{5}$ learning from experience, and learning through social interaction. The prevalence of one type of learning over the other in a given voluntary organization may be associated with the availability of non-formal programs, but also with the learning preferences of volunteers, which in turn may be related to their institutional affiliation. For instance, Ilsley (1990, p. 65), in a four-year study of volunteering in the United States, found out that in contrast to organization-centred volunteers, client-centred volunteers often reject formal training programs and learn primarily from the work itself.

In that study, Ilsley proposed three categories of volunteer learning (instrumental/didactic, social/expressive, and critical reflection) and noted an affinity between each type of learning and the ways of acquiring it. Instrumental/ didactic learning is often aimed at increasing the professional profile of volunteers; it is usually generated through standardized training programs to instill minimum levels of competence so volunteers can feel assured that they will have the intellectual tools they need for their assignments. Social/expressive learning refers to communication, trust, respect, compassion, and openness, which usually result from the volunteer experience rather than from courses or workshops. Critical reflection means turning inward, and deliberately analysing one's own politics, values, and priorities as well as those of society. This learning, also

bascia0053 15-11-04 11:50:40 Rev. 10*PS

Page Express (Manchester) Limited - Denton, Manchester, UK - 01613207424 
known in the literature as 'transformative learning' (Mezirow et al., 2001) is especially evident in volunteers involved in social and political movements and in those "who have made great sacrifices for the sake of a cause" (Ilsley 1990, p. 65). These volunteers tend to place value on learning political and social issues that are perceived as enhancing their social consciousness and their social vision, and as important to pursue their mission.

In Ilsley's typology of learning through volunteering, the first category is the easiest to identify and research (Ferguson, 2000; Kuhn, 1990; McCoy, 1996; Ojanlatva, 1991; Payne, 2001; Rayner \& Marshall, 2003; South Carolina State Department of Health and Environmental Control, 1991; Stenzel \& Feeney, 1968; Tedesco, 1991; Wilson, Steele, Thompson, \& D'Heron, 2002; Wisconsin Public Television, 1995). Generally, this instrumental/didactic learning is achieved through non-formal means, as it can be observed through the many manuals, textbooks, courses and workshops which are in place for the training and retention of volunteers and for ensuring that the volunteers have the necessary skills to do their work. It is the other two forms (social/expressive and critical reflection) that have a greater link to informal learning.

This does not mean, however, that instrumental skills cannot be acquired through informal learning. In a study on informal learning of front-line workers in the fast-food sector, and using a different typology, Grolnic (2001) identified three types of skills learned informally in the workplace: contextual (e.g., knowing the organization's values), intrapersonal and technical (e.g., making decisions, problem solving, improving job performance), and interpersonal (e.g., working with others). Grolnic concludes that there is much for schools to learn from examining how workers learn on the job. This examination should be broadened to include volunteer work given the importance of motivation to choice of volunteer work and to learning. Moreover, a better understanding of motivation can also help to further explore the links between what volunteers learn and why they volunteer. For example, if their main motivation for volunteering is normative (e.g., a concern for a certain cause like the environment, human rights, or homelessness) they are more likely to learn more about issues related to that particular cause and to strategies to advocate for it. However, if their motivation is primarily social (e.g., to interact with others, to become more confident in public, to develop leadership capacities) then they are more likely to improve their social skills (Ilsley, 1990, p. 64). Interestingly enough, these two areas (social and normative) are the most cited ones by volunteers when asked about the benefits derived from volunteering in community organizations. For instance, Chinman and Wandersman (1999) found that the most important benefits reported by volunteers are socializing with others (e.g., gaining personal recognition and respect from others) and the rewards of striving to reach the goals of the organization (e.g., make the community a safer place to live). Likewise, the two most frequent benefits reported by volunteers in the NSGVP were improvement of interpersonal skills (79\%) and communication skills (68\%) (Hall et al., 2001, p. 45).

Thus far, we have looked at the individual learning of volunteer workers. In

bascia0053 15-11-04 11:50:40 Rev. 10*PS

Page Express (Manchester) Limited - Denton, Manchester, UK - 01613207424 
their own attempt to categorize the seamless web of adult learning and change, Elsdon et al. (1995, p. 52) developed the following categories: Social and Group, Content, Occupational, Political, and Personal. From these categories, the first one is particularly interesting because Elsdon et al. argue that voluntary organizations learn as a group as well. In order to analyse such collective learning, they categorised the organizations as dynamic, static, or divergent.

"The dynamic are those which, at the time we studied them, were observably learning and developing. Another set appeared to be static in the sense that they were not undergoing any notable changes. The divergent were those which appeared to be in some kind of [contradictory] position in relation to their declared objectives" (Elsdon et al., 1995, p. 97).

These three concepts were only applied to the group learning aspect of the voluntary organizations. Interestingly, in spite of splitting out collective from individual learning, they found that the groups that saw the most individual learning also saw the most group learning. This was the case for both the more mature static groups and the dynamic ones. This led them to conclude that "high levels of individual learning and development, and of group learning and development, go together with an organization's commitment to learning and social or caring objectives" (Elsdon et al., 1995, p. 120). They also observed that two major ways of learning for voluntary organizations were through processes of internal reflection on group experience (a source for both individual and collective learning), and through networks.

\section{Policy Considerations}

Seven policy considerations arise from the previous sections. The first four appeal directly to volunteer organizations and communities that rely heavily on volunteers, and have to do with their own internal strategies for capacity building as well as with their connections with other organizations and agencies. The next two policy considerations deal with public agencies that mandate volunteer work. This includes the implementation of service learning programs in schools and other government agencies that mandate community service in order to receive social assistance. Although this troubles the notion of the freely chosen nature of a volunteer activity - consider that the term compulsory volunteer is an oxymoron - these developments are on the rise and should not be ignored in a discussion of voluntary work. The final policy consideration deals with the recognition of learning achieved through volunteer work either by educational institutions and/or by the labour market. A common theme permeating the seven policy considerations is the need for organizations to create enabling structures that maximize the individual and collective learning from the volunteer experience.

The first policy consideration relates to creating an ethos of volunteer participation within an organization. There are several ways in which this can happen:

bascia0053 15-11-04 11:50:40 Rev. 10*PS

Page Express (Manchester) Limited - Denton, Manchester, UK - 01613207424 
First, by having structures that encourage continuous volunteering through matching tasks to volunteer ability and interests. For instance, in our study on volunteer learning in housing co-ops, we noted that in those co-ops that offer a broader range of activities, responsibilities and possibilities for growth through committees, boards and other means, members tend to report greater satisfaction, continuity and repertoire of learning skills. Through our interviews, we have identified more than 30 specific areas of learning and change in relation to knowledge, skills, values and attitudes, and behaviours, ranging from a better understanding of the co-operative movement to leadership, managerial and clerical skills, from respecting diversity to facilitating democratic processes, from gardening to self-confidence, from finances and budgeting to conflict resolution, from civic engagement to concern for the common good. Similar findings were reported by Richmond and Mook (2001) in their study on the skills acquired by resident members in a student housing cooperative.

As a policy guideline for volunteer organizations, it becomes clear that the narrower the repertoire of volunteer experiences offered by the organization, and the scarcer the opportunities for reflecting on those experiences, the weaker the likelihood of significant learning and growth among volunteer participants. Providing enabling structures for volunteering and for learning implies the development of mechanisms and processes for identifying the talents, the needs and the interests of volunteers, linking these talents, needs and interests to meaningful volunteer experiences, creating new areas as required. It also implies providing opportunities for regular collective reflection, opening spaces for volunteer contributions to the wellbeing of the organization and for providing input for the improvement of processes, and encouraging volunteer participation in decision-making about matters that directly affect them.

A second way to create an ethos of volunteering is by including a social and caring element in the organization. As Elsdon et al. (1995) found, more individual and collective learning of volunteers took place in organizations that had not only learning objectives, but also social and caring ones. In terms of internal policy, if organizations focus at least some of their energy on the social element and on caring for volunteers, they are more likely to create conditions through which the tacit learning of volunteers can become explicit. That is, while nonformal training sessions or group reflections can lead to significant learning especially instrumental or didactic learning - a supportive organizational culture can contribute significantly to the informal learning of its volunteers.

A second policy consideration, which stems from the first one, relates to the continuous offering of non-formal educational experiences that are relevant, meaningful, innovative and enjoyable. This could include workshops, seminars, short courses, external or internal mentorship programs, and the like. While much of the learning in our lives takes place in informal ways, that does not mean that more formalised structures or systems do not also influence the learning potential. Designers and facilitators of these non-formal experiences should aim at linking both content and method to the informal and to the formal learning already acquired by volunteers. If an organization lacks the 
resources to offer what its members need at a given time, a pool of organizations with similar needs can be formed to develop initiatives together in a cost-effective way. By creating enabling structures for learning, even if they are just creating a chance for informal discussion between organization members, there is a directed nature to the learning experience. Simply planning to have coffee together as a group on a regular basis may not be considered non-formal learning - or at least not at the same level as a workshop - yet that simple structure may create conditions in which volunteers can reflect, articulate, and make explicit their tacit knowledge.

A third policy consideration has to do with the development of equalization mechanisms that provide relevant learning opportunities for the least disadvantaged members of a given community. If the quality of the volunteer experience and the responsibility for learning are left entirely to the individual volunteer, organizations are potentially obfuscating the role that systemic barriers may play in the process. In many organizations, the quality of the volunteer experience and the inherent level of decision-making are influenced by factors such as gender, race, class, age, professional and educational background, or physical disability. This tends to create an internal pyramid of 'high level volunteers' who lead and 'low level volunteers' who are assigned the more menial jobs and have the least opportunities for learning and growth. A labour distribution is often justified, as the functioning of an organization requires a great variety of tasks. However, to permanently confine certain members to certain roles is not only unfair but also inefficient for the improvement of the collective, as all members have actual and potential talents that can benefit the organization. This should not be left to random initiatives of goodwill but to clear policies of human development. If informal learning is going to challenge systems of oppression, enabling structures should be explicitly put in place to equalize opportunity (see for example Foley, 1999; Freire, 1970/2000).

A fourth policy consideration has to do with organizational learning. If the focus remains on the learning of individual volunteers, it is possible to miss some of the systemic factors that may be at play both within the organization and in its relationship with other social groups. Organizations can develop activities to put both individual and collective learning into social context. In what ways is a given organization mirroring or perpetuating systemic injustices and in what way is it challenging them? How is it learning from its interactions in society? The policy consideration here is the importance for groups to build opportunities to collectively reflect, both within their organization and with other groups, about their experiences. An example would be a voluntary organization that does service provision for a state agency. If there is not an opportunity for members to proactively reflect on what the organization is doing through its work as an agent of the state, then they will be less likely to consciously support or challenge given state policies related to their service provision.

A fifth policy consideration relates to the inclusion of community service in the school curriculum, an overlapping area between voluntary and mandatory work. In a school context, volunteer service policies can be found on a continuum 
from volunteer service opportunities to service-learning courses integral to a school's mission. As Andersen (1999, p. 2), observes, many schools or districts start with a policy that mandates service hours, and then move towards more service-learning. This type of evolution occurs because these policies are easier to plan and implement in terms of logistics (e.g., track hours, fill out forms, little to no formal assessment, little monitoring, etc). The two most contested policy issues in these initiatives are: a) the level of integration of the volunteer work experience into the curriculum and, b) whether participation in the program should be mandatory or not.

In relation to the integration issue, it seems that the greater the volunteer experience is integrated into the students' curriculum, the greater the learning potential (Westheimer \& Kahne, 1999). In their study about the impact of mandated 40 hours of volunteer service in Ontario for high school graduation, Foster \& Meinhard (2000) concluded that significant learning was

more likely to occur in programs in which students were obliged to keep a journal, in which time was set aside during class to talk about the experience and in which students designed the program for themselves as opposed to having it assigned.

That is not to say that any volunteer activity that is not integrated into the curriculum will not facilitate students' learning, but rather that the reliability of the results is less assured. Back to Andersen's point, it is clear why integrating the experience into the curriculum, even if it is seen as desirable, is not always carried out because of the extra work it creates.

In relation to the second issue, emerging studies suggest that mandatory community programs result in lower learning outcome than voluntary programs (Andersen, 1999; Foster \& Meinhard, 2000). These studies found that student autonomy was important to learning. If the students felt that they had some control over where and how they volunteered, they were likely to do so more willingly and to learn more from the experience. This research suggests that keeping the experience voluntary will reap greater rewards. In fact, Andersen found that schools without a mandatory component of volunteer service often have higher rates of participation in volunteer activities than those with mandatory components. What is important is making different volunteer opportunities available to students. Again, this means more work for the schools themselves, but if there is commitment to outcomes of an ethic of volunteering and helping society, then it seems that simply mandating volunteering without support in the form of finding placements and reflecting on learning, will not achieve the desired results (see also Loupe, 2000; Stukas, Snyder, \& Clary, 1999).

A sixth policy consideration relates to mandatory "volunteer" work or community service as part of social assistance plans, also referred to as workfare plans. It is beyond the scope of this piece to discuss all of the relevant literature on this topic (for a recent comprehensive review of research on workfare, see Steger, 2002). The reasons for mandating community service are generally twofold. First, to provide the social assistance recipient a chance to practice some 
new skills, brush up on some old ones, gain some recent experience and current references to build a résumé (Ontario Ministry of Community Family and Children's Services, 2003). Second, to give community organizations extra help. Regardless of the motivation behind them, at the level of policy implementation these policies may have a more punitive than educative effect. That is, unless there is sufficient support - as in the case above with schools - to reflect deliberately on the "volunteer" experience, the effect of a program can be more to punish people for needing social assistance rather than helping them to acquire skills, knowledge, and attitudes that would facilitate re-entry to the labour market. Again, and this connects to other policy considerations already mentioned, if the program is to meet educative rather than punitive objectives, it should include structures that enable reflections on the 'volunteer' experience.

Last but not least, a policy consideration relevant to the link between informal learning and volunteering work relates to issues of assessment and recognition. One of the most developed policy instruments in this regard is probably PLAR (Prior Learning Assessment and Recognition (PLAR), a technique for recognizing learning that has taken place outside of the formal educational system. It is in use by different educational institutions to give people without formal accreditation entry into programs or to give them advanced placement in their program. It is also in use in the workplace to recognize learning that workers do outside of the workplace that is relevant to their jobs (see Thomas, 1998 and www.nall.ca for a more complete review of PLAR). While each institution is ultimately responsible for their own PLAR system making it hard to generalize, policies need to recognize especially the tacit knowledge that is acquired through volunteering and find ways to encourage a reflective process. As mentioned above, the most significant learning for many volunteers is unpremeditated. It is important for PLAR policies to find ways to tease out such tacit learning so that they can be recognized. Additionally, portfolios prepared for a PLAR process can show the different activities and campaigns that a learner has completed through their volunteering.

\section{Summary and Conclusions}

After writing this chapter, it became clear to us that the great diversity of realities at both the individual and organization level, makes it very difficult to generalize about volunteer work, particularly about the learning that results from the activity. Having said that, prior studies on volunteer work suggest that learners are often unaware of the knowledge, skills and values acquired through the volunteer experience. Additionally, learners are often unaware of the ways and processes by which they learned. In our own research in progress, often the tacit knowledge of volunteers becomes explicit through the interview itself. Many interviewees comment: "I've never thought about that before, but I really did learn something from that experience", or "I didn't know how much I have learned; I am impressed!" Then, when we ask volunteers how they have learned, many reply that they don't know or say that they learned "just by doing it."

bascia0053 15-11-04 11:50:40 Rev. 10*PS

Page Express (Manchester) Limited - Denton, Manchester, UK - 01613207424 
Learning from experience in this way generally would fit into the category of informal learning.

Livingstone's (forthcoming, 2003) distinction between the different types of learning is useful because it gives more clarity to how things are being learned. It allows us to identify whether there is a more senior member of an organization acting as a mentor, or a deliberate attempt to reflect on past experiences, or whether the learning is more tacit in nature.

In terms of policy recommendations, we suggest that the amount, quality and diversity of volunteer learning experiences is more likely to increase if the organization creates an ethos of volunteer participation and provides enabling structures for a variety of volunteer opportunities that match the interests and needs of members. The quality of the learning experiences is also likely to increase if the organization combines non-formal educational initiatives with continuous reflective processes during and after each volunteer experience. These recommendations also apply to community service mandated by schools and other public agencies, whose programs are more likely to succeed if the volunteer dimension is stronger than the mandatory one and hence if volunteer motivation is higher.

There is also a need further develop and refine policies and programs for assessment and recognition of informal learning acquired through volunteer work by educational institutions and employers. In this regard, it is pertinent to note that some skills learned through volunteer work can be directly applied to careers (like in the case of computer software as discussed above), but other, more generic skills, are also important for formal workplaces. Indeed, certain social, interpersonal and organisational skills, critical reasoning and decisionmaking abilities, understanding a problem form someone else's perspective, developing a work ethic, working in groups, or examining one's values in relation to other people's values, are important ones, although they are difficult to measure and even more difficult to put a monetary value on them.

Finally, we suggest that the study of learning through volunteer work can inform educational initiatives in schools and training initiatives in the paid work sector. By uncovering the hidden world of informal learning, particularly in unpaid work, we can improve the pedagogical potential of non-educational agencies that nonetheless educate, and transfer important lessons to the world of formal educational institutions and paid workplaces. If the 21st century is going to become the century of a learning society we will have to generate a greater synergy among educational and non-educational institutions, creating an archipelago of learning communities that maximize our learning potential.

\section{Epilogue: Notes for a Research Agenda on Learning and Voluntary Work}

Because research on the connections between informal learning and volunteering is still in its infancy, more studies are needed in several areas. Two area for

bascia0053 15-11-04 11:50:40 Rev. 10*PS

Page Express (Manchester) Limited - Denton, Manchester, UK - 01613207424 
further research, suggested by Handy et al. (2000) has to do with public perceptions of voluntary work, and with measuring the net cost and benefit of a given volunteer activity. In future studies on these issues we suggest to include the notion of learning. For instance, what is the public perception on the nature of volunteering if learning is closely associated with the activity? Would people who learn a great deal from their volunteer work be seen as 'lesser volunteers' in the sense that they benefit from it) than those who do not? How to predict the individual and social impact of the future application of that learning to a particular purpose, and how would that be included in a cost/benefit analysis?

Another area for further research is exploring the connections between the type of volunteer work experience and the intensity and quality of the learning experience. If, as NALL suggests, informal learning tends to be more intense in voluntary work than in paid work, it is important to further explore whether this is a fact across the board or only in some types of voluntary work, and to determine the implications of this for training policies and programs, and for the assessment and recognition of informal learning as well. Although there are many studies on voluntary work in Canada, little is known yet about the extent, modes and effectiveness of volunteers' acquisition of new skills, knowledge, attitudes and values, and the relationship between formal, nonformal and informal learning in this process.

A related theme, which we just touched on in this chapter, deals with the degree of coercion in a given volunteer job and its impact on learning. A test of our six ideal types of volunteers, focusing on variables such as passion, social pressure and self-interest, might be an interesting place to explore the impact of mandatory volunteering on learning. What are the political and ethical ramifications of some mandating others to do volunteer work? What is the long-term impact of forced volunteering on the volunteer ethic? What do people learn about volunteering if they do not freely choose to volunteer? What happens when volunteer service is mandated by the state leaving individual schools and communities no choice but to implement the programs? What impact does this have on the learning opportunities that can be created for participants?

Further work needs to be done to understand the type of learning acquired through volunteer work. We are exploring this by looking at three different types of learning: cumulative, new, and transformative. Using this kind of lens hopefully gives a more nuanced understanding of what processes volunteers are using to learn. It would also be interesting to explore ways in which the tacit knowledge gained through volunteering is made explicit through enabling structures for informal learning and non-formal opportunities for reflection in different organizations. How can this be fostered within the day-to-day operations of voluntary organizations and how can the knowledge be made explicit for recognition by employers, educational institutions and society in general?

Another interesting question to explore in further research is whether voluntary organizations that have educational objectives (be it through direct services to students, like adult literacy, or through public education on broad issues such as environment, health and the like) are more likely to support the learning

bascia0053 15-11-04 11:50:40 Rev. 10*PS

Page Express (Manchester) Limited - Denton, Manchester, UK - 01613207424 
needs of volunteers than those organisations which do not focus on education. In other words, are educational organisations more sensitive to the educational needs of their volunteers and more committed to provide them with learning opportunities than non-educational organisations?

This preliminary list suggests that the field of volunteer learning still has more questions than answers, which is good news for researchers. Hopefully, this chapter is making a modest contribution to this collective inquiry, and helps to call public attention about the significance of informal learning from volunteer work, and about its potential role in the construction of an inclusive learning society.

\section{Notes}

1. Many newcomers are unable to find work in Canada in spite of meeting the job qualifications and professional licensing requirements; often they have to volunteer in order to get Canadian experience which they hope will help them find work in their profession.

2. This survey was conducted by Statistics Canada in 1997 and 2000 and will be conducted again in 2003. It is the only survey of its kind in Canada that explores the philanthropy, volunteering and participation of Canadians.

3. We are well aware that especially in the case of immigrants, the major beneficiary is the organization/corporation employing the volunteer but conceptually, the beneficiary can be construed as the individual.

4. To take a different example related to more instrumental learning, one participant in our study noted that had the opportunity to volunteer in a nonprofit agency organising a conference. Because he already had a certain level of computer knowledge, he was given the task of organising the computer database to track conference registrations. Other volunteers without the same cultural capital would be given tasks such as collecting tickets at the door at the day of the conference. This participant was later able to transfer the new addition to his cultural capital to a paid position for another organisation, which he found thanks to his connections (social capital). Meanwhile, volunteers who worked as ushers and other low skilled tasks for the conference would have had much greater difficulty translating their learning into paid employment.

5. We acknowledge that sometimes apprenticeship training can be implemented through formal and nonformal methods.

\section{References}

Abdennur, A. (1987). The conflict resolution syndrome: Volunteerism, violence and beyond. Ottawa: University of Ottawa Press.

Abers, R. (2000). Inventing local democracy: Grassroots politics in Brazil. Boulder, Co.: Lynne Rienner Publishers.

Andersen, S. M. (1999). Mandatory community service: Citizenship education or involuntary servitude? Issue Paper. Denver, CO: Education Commission of the State.

Baiocchi, G. (1999). Participation, activism, and politics: The Porto Alegre experiment and deliberative democratic Theory. Retrieved April 28, 2001, from http:/www.ssc.wisc.edu/ wright/ Baiocchi.PDF

Billett, S. (2001). Learning in the workplace: strategies for effective practice. Crows Nest, Australia: Allen \& Unwin.

Bourdieu, P. (1986). The forms of capital (R. Nice, Trans.). In J. Richardson (Ed.), Handbook of theory and research for the sociology of education (pp. 241-258). New York: Greenwood Press.

bascia0053 15-11-04 11:50:40 Rev. 10*PS

Page Express (Manchester) Limited - Denton, Manchester, UK - 01613207424 
Brudney, J. (1990). Fostering volunteer programs in the public sector. San Francisco: Jossey-Bass.

Chinman, M., \& Wandersman, A. (1999). The benefits and costs of volunteering in community organizations: Review and practical implications. Nonprofit and Voluntary Sector Quarterly, 28(1), $46-63$.

Clover, D. E., \& Hall, B. L. (2000). In search of social movement learning: The growing jobs for living project. NALL Working Paper. Retrieved December 5, 2002, from http://www.oise.utoronto.ca/ depts/sese/csew/nall/res/18insearchof.htm

Cnaan, R. A., Handy, F., \& Wadsworth, M. (1996). Defining who is a volunteer: Conceptual and empirical considerations. Nonprofit and Voluntary Sector Quarterly, 25(3), 364-383.

Cox, E. (2002). Rewarding volunteers: A study of participant responses to the assessment and accreditation of volunteer learning. Studies in the Education of Adults, 34(2), 156-170.

Elsdon, K. T. (1995). Values and learning in voluntary organizations. International Journal of Lifelong Education, 14(1), 75-82.

Elsdon, K. T., Reynolds, J., \& Stewart, S. (1995). Voluntary organisations: Citizenship, learning and change. Leicester, England: NIACE (National Organization for Adult Learning) \& Department of Adult Education University of Nottingham.

Ferguson, R. M. (2000). An evaluation of the Carbondale Women's Center volunteer training program (Illinois). Unpublished PhD thesis, Southern Illinois University, Carbondale.

Foley, G. (1999). Learning in social action:Aa contribution to understanding informal education. New York: Zed.

Foster, M. K., \& Meinhard, A. G. (2000). "Structuring Student Volunteering Programs to the Benefit of Students and the Community: The Ontario Experience" presented at the International Society for Third-Sector Research Fourth International Conference: Dublin, July 5-8, 2000. Retrieved June 13, 2003, from http://www.jhu.edu/ istr/conferences/dublin/abstracts/foster-meinhard.html

Freire, P. (1970/2000). Pedagogy of the oppressed: 30th anniversary edition. New York: Continuum.

Government of Ontario. (1997). Ontario Works Act, 1997. Retrieved June 13, 2003, from http:// 192.75.156.68/DBLaws/Statutes/English/97o25a_e.htm

Grolnic, S. (2001). Informal learning in the workplace: What can be learned doing a McJob? Unpublished PhD Thesis, Harvard University.

Hall, M., McKeown, L. E., Roberts, K., Canadian Centre for Philanthropy, \& Statistics Canada. (2001). Caring Canadians, involved Canadians: highlights from the 2000 National Survey of Giving, Volunteering and Participating. Ottawa: Statistics Canada.

Handy, F., Cnaan, R. A., Brudney, J. L., Ascoli, U., Meijs, L. C. M. P., \& Ranade, S. (2000). Public perception of "Who is a volunteer": An examination of the net-cost approach from a cross-cultural perspective. Voluntas: International Journal of Voluntary and Nonprofit Organizations, 11(1), 45-65.

Hustinx, L., \& Lammertyn, F. (2003). Collective and reflexive styles of volunteering: A sociological modernization perspective. Voluntas: International Journal of Voluntary and Nonprofit Organizations, 14(2), 167-187.

Illich, I. (1970). Deschooling society. NY: Longman.

Ilsley, P. J. (1990). Enhancing the volunteer experience: New insights on strengthening volunteer participation, learning, and commitment. San Francisco: Jossey-Bass.

Kuhn, A. (1990). A handbook for volunteer coordinators in Head Start (ERIC Document: ED396828). District of Columbia.

Livingstone, D. W. (1999). Exploring the icebergs of adult learning: Findings of the First Canadian Survey of Informal Learning Practices. Canadian Journal for the Study of Adult Education, 13(2), $49-72$.

Livingstone, D. W. (2001a). Adults' Informal Learning: Definitions, Findings, Gaps and Future Research. NALL Website, www.nall.ca

Livingstone, D. W. (2001b). Basic patterns of work and learning in Canada: Findings of the 1998 NALL survey of informal learning and related Statistics Canada surveys. http://www.oise.utoronto.ca/depts/ sese/csew/nall/res/33working\&learning.htm

Livingstone, D. W. (forthcoming, 2003). Informal learning: Conceptual distinctions and preliminary findings. In Z. Bekerman, N. Burbules \& D. Silberman (Eds.), Learning in hidden places: The informal education reader. New York: Peter Lang.

bascia0053 15-11-04 11:50:40 Rev. 10*PS

Page Express (Manchester) Limited - Denton, Manchester, UK - 01613207424 
Loupe, D. (2000). Community Service: Mandatory or Voluntary? School Administrator, 57 (7), 32-34, $36-39$.

McCoy, M. (1996). Planning community-wide study circle programs. A step-by-step guide (ERIC Document: ED391940). Connecticut: Study Circles Resource Center.

Merrifield, J. (2001). Learning citizenship:Learning from experience and trust. Retrieved May 27, 2003, from http://www.commonwealthfoundation.com/documents/learning.pdf

Mezirow, J., \& Associates (2001). Learning as transformation. Critical perspectives on a theory in progress. San Francisco: Jossey-Bass.

Ojanlatva, A. (1991). Training volunteers for an AIDS buddy program. (ERIC Document Reproduction Service No. ED336378).

Ontario Ministry of Community Family and Children's Services (2003). Employment assistance. Retrieved June 14, 2003, from http://www.cfcs.gov.on.ca/CFCS/en/programs/IES/OntarioWorks/ employmentAssistance/default.htm

Ontario Ministry of Education and Training (1999). Ontario Secondary Schools Grades 9-12, Program and Diploma Requirements 1999. Retrieved June 13, 2003, from http://mettowas21.edu.gov.on.ca/ eng/document/curricul/secondary/oss/oss.pdf

Oxford English Dictionary (2003). Oxford English Dictionary: volunteer. Retrieved April 21, 2003, from http://www.chass.utoronto.ca/patbin/new/oed-idx?fmt $=$ entry\&type $=$ entry\&byte $=$ 543111921

Pateman, C. (1970). Participation and democratic theory. Cambridge: University Press.

Payne, S. (2001). The role of volunteers in hospice bereavement support in New Zealand. Palliative Medicine, 15(2), 107-115.

Percy, K., Barnes, B., Graddon, A., \& Machell, J. (1988). Learning in voluntary organisations (ERIC Document: ED318890): National Institute of Adult Continuing Education, Leicester, England.

Polanyi, M. (1966). The tacit dimension. New York: Doubleday.

Quarter, J., Mook, L., \& Richmond, B. J. (2003). What counts: Social accounting for nonprofits and cooperatives. Upper Saddle River, NJ: Prentice Hall.

Rayner, H., \& Marshall, J. (2003). Training volunteers as conversation partners for people with aphasia. International Journal of Language \& Communication Disorders, 38(2), 149-164.

Richmond, B. J., \& Mook L. (2001). Social audit report for Waterloo Co-operative Residence Incorporated (WCRI). Toronto: Author.

Roker, D., Player, K., \& Coleman, J. (1999). Young people's voluntary and campaigning activities as sources of political education. Oxford Review of Education, 25(1-2), 185-198.

Salamon, L. M., Anheier, H. K., List, R., Toepler, S., Sokolowski, S. W., \& Associates. (1999). Global civil society: Dimensions of the nonprofit sector. Baltimore: The Johns Hopkins Centre for Civil Society Studies.

Salamon, L., \& Sokolowski, W. (2002). Institutional roots of volunteering: Towards a macro-structural theory of individual voluntary action. Paper presented at ARNOVA Conference. Montreal, Canada, November 14-16.

Schugurensky, D. (2000). The forms of informal learning: Towards a conceptualization of the field. NALL working paper \#19-2000. Retrieved August 28, 2003, from http://www.oise.utoronto.ca/ depts/sese/csew/nall/res/19formsofinformal.htm

Schugurensky, D. (2001). Grassroots democracy: The participatory budget of Porto Alegre. Canadian Dimension, 35(1), 30-32.

Schugurensky, D. (2002). Transformative learning and transformative politics: The pedagogical dimension of participatory democracy and social action. In E. O'Sullivan, A. Morrell \& M. A. O'Connor (Eds.), Expanding the boundaries of transformative learning: essays on theory and praxis (pp. 59-76). New York: Palgrave.

Sheard, J. (1995). From lady bountiful to active citizen: Volunteering and the voluntary sector. In J. D. Smith, C. Rochester \& R. Hedley (Eds.), An introduction to the voluntary sector. New York: Routledge.

South Carolina State Department of Health and Environmental Control. (1991). Volunteer training manual. Bureau of Home Health and Long Term Care. Columbia, SC.

bascia0053 15-11-04 11:50:40 Rev. 10*PS

Page Express (Manchester) Limited - Denton, Manchester, UK - 01613207424 
Steger, M. A. E. (2002). Welfare reform: Process, participation, discourse, and implications. The Journal of Politics, 64(3), 914-918.

Stenzel, A. K., \& Feeney, H. M. (1968). Volunteer training and development; A manual for community groups. New York: Seabury Press.

Stukas, A. A., Snyder, M., \& Clary, E. G. (1999). The effects of "mandatory volunteerism" in intentions to volunteer. Educational Horizons, 77(4), 194-201.

Tedesco, J. E. (1991). Catholic schools and volunteers: A planned involvement. Washington: National Catholic Educational Association.

Thomas, A. M. (1998). The tolerable contradictions of prior learning assessment. In S. M. Scott, B. Spencer \& A. M. Thomas (Eds.), Learning for life: Canadian readings in adult education (pp. 330-342). Toronto: Thompson Educational Publishing.

Tough, A. (1971). The adult's learning projects. Toronto: OISE Press.

Westheimer, J., \& Kahne, J. (1999). Service learning as democratic action. Educational Horizons, $77(4), 186-193$.

Westheimer, J., \& Kahne, J. (2002). What kind of citizen? The politics of educating for democracy. Paper presented at the Annual Meeting of the American Educational Research Association, New Orleans, LA

Wilson, L., Steele, J., Thompson, E., \& D'Heron, C. (2002). The leadership institute for active aging: A volunteer recruitment and retention model. Journal of Volunteer Administration, 20(2), 28-36.

Wisconsin Public Television and Wisconsin State Department of Public Instruction. (1995). School volunteer resource guide. Madison, WI.

bascia0053 15-11-04 11:50:40 Rev. 10*PS

Page Express (Manchester) Limited - Denton, Manchester, UK - 01613207424 